\title{
Role of Glutathione Transferases in the Mechanism of Brostallicin Activation
}

Silvia Pezzola, ${ }^{\ddagger}$ Giovanni Antonini, ${ }^{\S}$ Cristina Geroni," Italo Beria," Maristella Colombo,, Massimo Broggini, ${ }^{\perp}$ Nicola Mongelli," Loris Leboffe, ${ }^{\S}$ Robert MacArthur, ${ }^{@}$ Alessia Francesca Mozzi, ${ }^{\#}$ Giorgio Federici,,${ }^{\nabla}$ and Anna Maria Caccuri*,

\author{
${ }^{\star}$ Department of Chemical Sciences and Technologies, University of "Tor Vergata”, Rome, Italy, ${ }^{\S}$ Department of Biology, University of \\ "RomaTre”, Rome, Italy, "Nerviano Medical Sciences Srl, Oncology, Nerviano, Italy, ${ }^{\perp}$ Laboratory of Molecular Pharmacology, \\ Istituto di Ricerche Farmacologiche 'Mario Negri', Milan, Italy, ${ }^{@}$ Systems Medicine LLC, a wholly owned subsidiary of \\ Cell Therapeutics Inc., Seattle, Washington, ${ }^{*}$ Laboratory of clinical biochemistry, TorVergata's Hospital, Rome, Italy, and \\ $\nabla$ Children's Hospital, Istituto di Ricovero e Cura a Carattere Scientifico "Bambin Gesù", Rome, Italy
}

\section{Received September 28, 2009; Revised Manuscript Received December 1, 2009}

\begin{abstract}
Brostallicin is a novel and unique glutathione transferase-activated pro-drug with promising anticancer activity, currently in phase I and II clinical evaluation. In this work, we show that, in comparison with the parental cell line showing low GST levels, the cytotoxic activity of brostallicin is significantly enhanced in the human breast carcinoma MCF-7 cell line, transfected with either human GST- $\pi$ or GST- $\mu$. Moreover, we describe in detail the interaction of brostallicin with GSH in the presence of GSTP1-1 and GSTM2-2, the predominant GST isoenzymes found within tumor cells. The experiments reported here indicate that brostallicin binds reversibly to both isoenzymes with $K_{\mathrm{d}}$ values in the micromolar range (the affinity being higher for GSTM2-2). Direct evidence that both GSTP1-1 and GSTM2-2 isoenzymes catalyze the Michael addition reaction of GSH to brostallicin has been obtained both by an HPLC-MS technique and by a new fluorometric assay. We also saw the rapid formation of an intermediate reactive species, which is slowly converted into the final products. This intermediate, identified as the $\alpha$-chloroamido derivative of the GSH-brostallicin adduct, is able to alkylate DNA in a sequence-specific manner and appears to be the active form of the drug. The kinetic behavior of the reaction between brostallicin and GSH, catalyzed by GSTP1-1, has been studied in detail, and a minimum kinetic scheme that suitably describes the experimental data is provided. Overall, these data fully support and extend the findings that brostallicin could be indicated for the treatment of tumor overexpressing the pi or mu class GST.
\end{abstract}

Brostallicin 1 (Figure 1) is an anticancer agent under evaluation in phase I and II clinical trials (1). This synthetic compound is a DNA minor groove binding drug characterized by an $\alpha$-bromoacrylamido moiety tethered to a distamycin-like frame (Figure 1). In vitro and in vivo experiments show that it is active against a variety of experimental murine and human tumors when used as a single agent. It also displays synergistic activity when combined with either mechanistically classical or novel molecular-targeted drugs $(2,3)$. Brostallicin circumvents tumor resistance mechanisms known to inactivate alkylating agents, platinum derivatives, and camptothecins, maintains efficacy in mismatch repairdeficient cells, and is very active in inducing apoptosis (3-7). Even though brostallicin and its chloroacrylamido derivative $\mathbf{2}$ (Figure 1) have a significant cytotoxic effect on tumor cells, brostallicin appears unreactive in classical DNA alkylation assays (8). Therefore, it has been hypothesized that the drug may be activated by an intracellular reactive nucleophilic species that could perform a first-step Michael-type attack on the double bond, forming a reactive adduct able to bind covalently to the minor groove of DNA (9). Furthermore, experimental evidence suggests that human glutathione transferases (GSTs, ${ }^{1}$ EC

*To whom correspondence should be addressed: Department of Chemical Sciences and Technologies, University of "Tor Vergata", Via della Ricerca Scientifica, 00133 Rome, Italy. Telephone: 390672596204. Fax: 39-0672594328. E-mail: caccuri@uniroma2.it.

${ }^{1}$ Abbreviations: GST, glutathione transferase; GSH, glutathione; CDNB, 1-chloro-2,4-dinitrobenzene; TFA, trifluoroacetic acid; HPLC, high-performance liquid chromatography; MS, mass spectrometry; Taq, Thermophilus aquaticus; PCR, polymerase chain reaction.
2.5.1.18) are essential for the activation of brostallicin. In fact, the human mu and pi class GST isoenzymes decrease the half-life of brostallicin in solution (4). This drug was also found to be significantly more active on tumor cell lines overexpressing the pi class isoenzyme GSTP1-1 $(3,10)$. Accordingly, in vivo experiments show that cancer cells overexpressing GSTP1-1, due to transfection of GSTP1-1 cDNA, are more sensitive to brostallicin in comparison with tumor cells with lower GSTP1-1 levels $(3,10)$. Thus, brostallicin has been hypothesized to be a GST-activated pro-drug, i.e., a molecule that exploits GST catalytic power for activation into a cytotoxic agent. In this study, we confirm this hypothesis by highlighting the role of different GST isoenzymes in the brostallicin activation mechanism. We used multiple and distinct experimental approaches to study in detail the nature of the interaction of brostallicin with GSTP1-1 and GSTM2-2, the most abundant GST isoenzymes in human tumor cells $(11,12)$. The obtained data lead to the conclusion that both GSTs catalyze the formation of a transient $\alpha$-chloroamido derivative of the $\mathrm{GSH}$-brostallicin adduct. We further analyzed the reactivity of brostallicin and its $\alpha$-chloroamido derivative in a DNA alkylation assay, reaching the conclusion that the transient derivative could represent the active form of the drug.

\section{EXPERIMENTAL PROCEDURES}

Materials. 1-Chloro-2,4-dinitrobenzene (CDNB) and GSH were obtained from Sigma Chemical Co. Brostallicin 1 (PNU166196) and its debrominated derivative 3 were synthesized at Nerviano Medical Sciences Srl (Nerviano, Italy). Brostallicin-GSH 


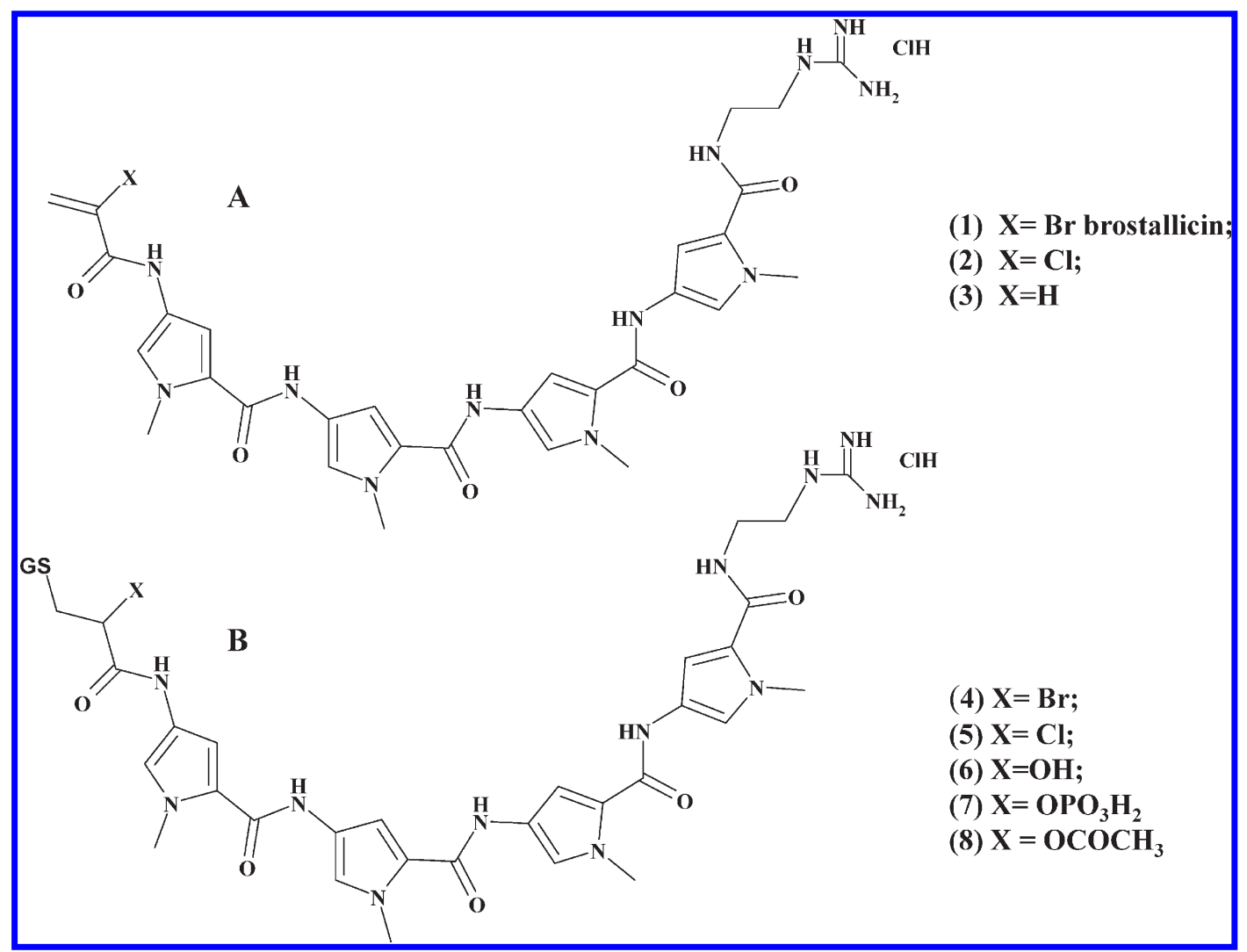

Figure 1: (A) Structure of brostallicin (PNU-166196) (1) and analogues. (B) Structure of the brostallicin-GSH adduct (4) and derivatives.

adducts 6 and 7 were generated after a prolonged incubation $(\sim 3 \mathrm{~h})$ of brostallicin $(100 \mu \mathrm{M})$ with GSH $(1 \mathrm{mM})$ and GSTP1-1 $(1 \mu \mathrm{M})$ in either $0.1 \mathrm{M}$ potassium phosphate buffer ( $\mathrm{pH} 6.5$ ) to yield a mixture of compounds $\mathbf{6}$ and $\mathbf{7}$ or aqueous solution (no buffer), adjusting the acid solution to $\mathrm{pH} 6.5$ with diluted $\mathrm{NaOH}$, to yield only compound $\mathbf{6}$.

Cell Lines and Drug Sensitivity. The MCF-7 human breast carcinoma cell line and its clones overexpressing the human GST$\pi$ (MCF- $7 \pi)$, GST- $\mu$ (MCF- $7 \mu$ ), or GST- $\alpha$ (MCF-7 $\alpha$ ) gene were obtained and grown as reported previously $(13,14)$. All the clones overexpress the specific transfected isoform, and they have an increased GST activity, measured using CDNB as the substrate, over parental cells $(13,14)$. All cell lines were maintained at $37^{\circ} \mathrm{C}$ and $5 \% \mathrm{CO}_{2}$ in medium supplemented with $10 \%$ fetal calf serum. Drug-induced cytotoxicity was determined by a intracellular ATP monitoring system (CellTiterGlo-Promega) using the Envision (PerkinElmer) as a reader. Exponentially growing cells were seeded and exposed to various drug concentrations. The antiproliferative activity of brostallicin was evaluated by comparing treated versus vehicle-treated control cells using Assay Explorer (MDL). The dose inhibiting cell growth by $50 \%\left(\mathrm{IC}_{50}\right)$ was calculated using a sigmoidal interpolation curve.

Enzymes. Recombinant GSTP1-1 and GSTM2-2 were expressed in Escherichia coli and purified as previously described (15). GST activity was measured at $25{ }^{\circ} \mathrm{C}$ in $1 \mathrm{~mL}$ (final volume) of $0.1 \mathrm{M}$ potassium phosphate buffer ( $\mathrm{pH}$ 6.5) containing EDTA $(0.1 \mathrm{mM})$, GSH $(1 \mathrm{mM})$, and CDNB $(1 \mathrm{mM})$ as a cosubstrate. The activity was followed spectrophotometrically at $340 \mathrm{~nm}$, where the GS-DNB reaction product absorbs $(\varepsilon=$ $9.6 \mathrm{mM}^{-1} \mathrm{~cm}^{-1}$ ) (16). Protein concentrations were calculated from the absorbance at $280 \mathrm{~nm}$ assuming $\varepsilon_{1 \mathrm{mg} / \mathrm{mL}}$ values of 1.30 and 1.48 for GSTP1-1 and GSTM2-2, respectively. The extinction coefficient was calculated on the basis of the amino acid sequence as reported by Gill et al. (17) and confirmed by the bicinchoninic acid method (Pierce). Enzyme molarity was calculated referring to a single subunit. Molecular masses of 23 and $25.6 \mathrm{kDa}$ per GST subunit were used in the calculations for GSTP1-1 and GSTM2-2, respectively.

GST Inhibition Experiments. The interaction between the GSTs and brostallicin was determined, at $25^{\circ} \mathrm{C}$ and $\mathrm{pH} 6.5$, by measuring the decrease in GST activity in the presence of different concentrations of drug (between 0 and $50 \mu \mathrm{M}$ with GSTP1-1 and between 0 and $1 \mu \mathrm{M}$ with GSTM2-2). At each brostallicin concentration, either the CDNB or the GSH concentration was varied from 0.25 to $2 \mathrm{mM}$, while the cosubstrate concentration was maintained constant at $1 \mathrm{mM}$. Initial velocity data were reported as double-reciprocal plots. Apparent inhibition constants $\left(K_{\mathrm{i}}\right)$ were calculated by replot analysis of the primary reciprocal plots (18). The interaction of the GSTs with compound 3 (from 0 to $50 \mu \mathrm{M}$ ), 6 (from 0 to $20 \mu \mathrm{M}$ ), or a mixture of $\mathbf{6}$ and 7 (from 0 to $20 \mu \mathrm{M}$ ) was evaluated by measuring the decrease in GST activity at $\mathrm{pH} 6.5,25^{\circ} \mathrm{C}$, and fixed GSH and CDNB concentrations $(1 \mathrm{mM})$. $\mathrm{IC}_{50}$ values (the concentration of inhibitor that gives $50 \%$ of the reaction rate of the control reaction) were derived from the fit of data to a simple binding isotherm.

HPLC-UV/MS Evidence of the Reaction between GSH and Brostallicin. The time course of the GST-catalyzed reaction between GSH and brostallicin was followed by using a HPLCUV/MS technique. In a typical experiment, brostallicin $(100 \mu \mathrm{M})$ and GSH $(1 \mathrm{mM})$ were incubated at $25^{\circ} \mathrm{C}$ in $0.1 \mathrm{M}$ potassium phosphate buffer ( $\mathrm{pH} 6.5$, adjusted to $\mathrm{pH} 6.5$ with diluted $\mathrm{HCl}$ ) containing either $1 \mu \mathrm{M}$ GSTP1-1 or $1 \mu \mathrm{M}$ GSTM2-2. Alternatively, the same reaction was performed in $0.1 \mathrm{M}$ sodium acetate buffer ( $\mathrm{pH}$ 6.5). Aliquots were taken at the indicated times, and the reaction was stopped by addition of TFA (final concentration of $1 \%)$. HPLC-UV/MS analyses of samples $(20 \mu \mathrm{L})$ were 
conducted by combining the ion trap MS instrument with the SSP4000 HPLC system (Thermo Separation Products) equipped with an LC Pal autosampler (CTC Analytics) and a UV6000LP diode array detector (UV detection from 215 to $400 \mathrm{~nm}$ ). Instrument control, data acquisition, and processing were performed by using Xcalibur version 1.2 (Finnigan). HPLC was conducted at room temperature, with a $1 \mathrm{~mL} / \mathrm{min}$ flow rate, using a Waters XBridge RP 18 column $(4.6 \mathrm{~mm} \times 50 \mathrm{~mm}, 2.5 \mu \mathrm{m})$. Mobile phase A consisted of ammonium acetate $5 \mathrm{mM}$ buffer (pH 5.5 with acetic acid) and acetonitrile (90:10), and mobile phase B consisted of ammonium acetate $5 \mathrm{mM}$ buffer $(\mathrm{pH} 5.5$ with acetic acid) and acetonitrile (10:90); the gradient was from 0 to $100 \% \mathrm{~B}$ over $7 \mathrm{~min}$ then $100 \% \mathrm{~B}$ for $2 \mathrm{~min}$ before reequilibation. The ion trap spectrometer was operated in the full scan positive ion mode, in a range from $\mathrm{m} / \mathrm{z} 50$ to 1500 . The compounds were detected as $m / z[\mathrm{M}+\mathrm{H}]^{+}$.

HPLC-MS Analysis of Brostallicin-GSH Adducts Formed in Water (no buffer) and in Buffer Solutions. Brostallicin-GSH adduct $\mathbf{6}$ and a mixture of $\mathbf{6}$ and $\mathbf{7}$ were obtained as reported in Materials. Compounds were controlled using an Dionex Ultimate 3000 series HPLC system interfaced with a triple-quadrupole MDS Sciex (Foster City, CA) API 3000 mass spectrometer equipped with a Turboionspray (ESI). Detection of positive ions $[\mathrm{M}+\mathrm{H}]^{+}$was performed in multiple-reaction monitoring (MRM) mode, monitoring the transition of the $\mathrm{m} / \mathrm{z}$ 968 precursor ion to the $m / z 695$ and 839 product ions for compound $\mathbf{6}$ and of the $m / z 1048$ precursor ion to the $m / z 645$ and 951 product ions for compound 7.

Spectrofluorometric Evidence of the Reaction between Brostallicin and GSH. GST activity with GSH and brostallicin as substrates was measured at $\mathrm{pH} 6.5$ in a single-photon counting spectrofluorometer (Perkin-Elmer LS50B) with a sample holder set at $25^{\circ} \mathrm{C}$. Excitation was at $370 \mathrm{~nm}$, and emission was collected at $425 \mathrm{~nm}$. The increase in fluorescence intensity was measured after the addition of a suitable amount of GST to $1 \mathrm{~mL}$ (final volume) of $0.1 \mathrm{M}$ potassium phosphate buffer ( $\mathrm{pH}$ 6.5) (adjusted to $\mathrm{pH} 6.5$ with diluted $\mathrm{HCl}$ ), containing $0.1 \mathrm{mM}$ EDTA, and different amounts of substrates. In particular, steady-state reaction kinetics between GSH and brostallicin were studied with either 1 $\mu \mathrm{M}$ GSTP1-1 or $1 \mu \mathrm{M}$ GSTM2-2, by varying either the GSH concentration from 1 to $20 \mathrm{mM}$ (keeping the brostallicin concentration constant at $50 \mu \mathrm{M}$ ) or the brostallicin concentration from 1 to $100 \mu \mathrm{M}$ (keeping the GSH concentration constant at $1 \mathrm{mM}$ ). The dependence of steady-state velocity on substrate concentration was fitted to a simple binding isotherm to calculate the apparent Michaelis constants $\left(K_{\mathrm{m}}\right)$.

Kinetic Analysis of the Brostallicin-GSH Reaction Catalyzed by GSTP1-1. The fluorescence time course of the reaction between brostallicin and GSH in the presence of variable amounts of GST was fitted to Scheme 1 to yield the microscopic rate constants and the thermodynamic constants listed in Table 2. COPASI version 4.4.27 (19) carried out the simultaneous fitting of the observed time courses to Scheme 1 by means of numerical integration of the ordinary differential equations. By using numerical integration, we also obtained the simulated time dependences of the observed events.

Taq Polymerase Stop Assay. This assay is a linear amplification method employing the properties of DNA polymerase in investigating the sequence selectivity of the interaction between DNA-damaging agents and DNA. Studies with the Taq stop assay were based on a previously reported method (20). Plasmid pBSSK-TOPO II was linearized with a PstI restriction enzyme
(NEB), to provide a stop for the Taq polymerase downstream from the primer, and then incubated at $\mathrm{pH} 7.2$ with either compound $\mathbf{5}$ or brostallicin in the absence or presence of the $\mathrm{GSH} /$ GST system. As a control, plasmid DNA was incubated with the DNA minor groove binding compound tallimustine at concentrations reported to produce alkylation at the $5^{\prime}$-TTTTGA target hexamer (2l). After drug treatment, the DNA was precipitated and washed as described previously (20). The primer was 50-endlabeled with T4 polynucleotide kinase (NEB) and $\left[\gamma_{-}{ }^{32} \mathrm{P}\right] \mathrm{ATP}$ (5000 $\mathrm{Ci} \mathrm{mmol}^{-1}$, Amersham). The synthetic primer sequence and the linear PCR amplification conditions were followed as described previously (21). Samples were then purified by extraction with an equal volume of chloroform and isoamyl alcohol (24:1), precipitated, and washed. Dried samples were resuspended in loading buffer and denatured at $90{ }^{\circ} \mathrm{C}$ for $2 \mathrm{~min}$ before being loaded onto an $8 \%$ polyacrylamide denatured gel. After the run, the gel was dried and autoradiographed.

\section{RESULTS}

Sensitivity to Brostallicin Is Higher in Cells Overexpressing either the GST- $\pi$ or the GST- $\mu$ Gene. The cytotoxic activity of brostallicin was evaluated in the human breast carcinoma MCF-7 parental cell line and in previously characterized clones, transfected with the human GST- $\pi$, GST- $\mu$, or GST$\alpha$ gene, showing GST levels higher than those found in parental cells $(13,14)$. GST- $\pi$ - and GST- $\mu$-overexpressing cells were 9-fold more susceptible to the cytotoxic activity of brostallicin than the empty vector-transfected MCF-7 cells (Table 1). Brostallicin was only 2-fold more cytotoxic in GST- $\alpha$-transfected MCF-7 cells which was in agreement with previously published data showing that the human mu and pi class GST isoenzymes were stronger activators than the alpha class GST isoenzyme (4). Moreover, the debrominated derivative of brostallicin, compound 3, when compared with brostallicin on MCF-7 cells, was found to be 1000 -fold less cytotoxic than the parent drug, and its potency was not dependent of GST expression (data not shown).

HPLC-UV/MS Evidence of the Reaction between Brostallicin and GSH. The GSH and brostallicin reaction time course was followed via a HPLC-UV system connected to a mass spectrometer, permitting compound identification. The rate of spontaneous reaction between GSH $(1 \mathrm{mM})$ and brostallicin $(100 \mu \mathrm{M})$ was negligible at $\mathrm{pH} 6.5$ in the absence of GST. However, in the presence of either GSTM2-2 (Figure 2A) or GSTP1-1 (Figure 2B), a decrease in brostallicin concentration and synchronous formation of a few GSH adducts were observed. Moreover, the reaction in the presence of GSTP1-1 occurred at a rate $\sim 4$ times higher than that with GSTM2-2.

Table 1: Brostallicin Efficacy on a Human Breast Tumor Cell Line (MCF7) Overexpressing or Not Different GST Isoenzymes ${ }^{a}$

\begin{tabular}{ccccc}
\hline & \multicolumn{4}{c}{$\mathrm{IC}_{50}(\mu \mathrm{M}) \pm \mathrm{SD}$} \\
\cline { 2 - 5 } drug & MCF-7 neo & MCF-7 $\pi$ & MCF-7 $\mu$ & MCF-7 $\alpha$ \\
\hline brostallicin & $0.55 \pm 0.1$ & $0.06 \pm 0.00$ & $0.06 \pm 0.00$ & $0.24 \pm 0.01$ \\
\hline
\end{tabular}

${ }^{a}$ Brostallicin activity was tested in isogenic human tumor cell lines differing in the expression of the GST isoenzyme. MCF7 cells overexpressing pi and mu class GST isoenzymes are more sensitive to brostallicin compared to the parental cells which do not express GST. $\mathrm{IC}_{50}$ is the dose causing $50 \%$ inhibition of colony growth in treated culture vs untreated controls. Values are means of four independent experiments. SD is the standard deviation. 


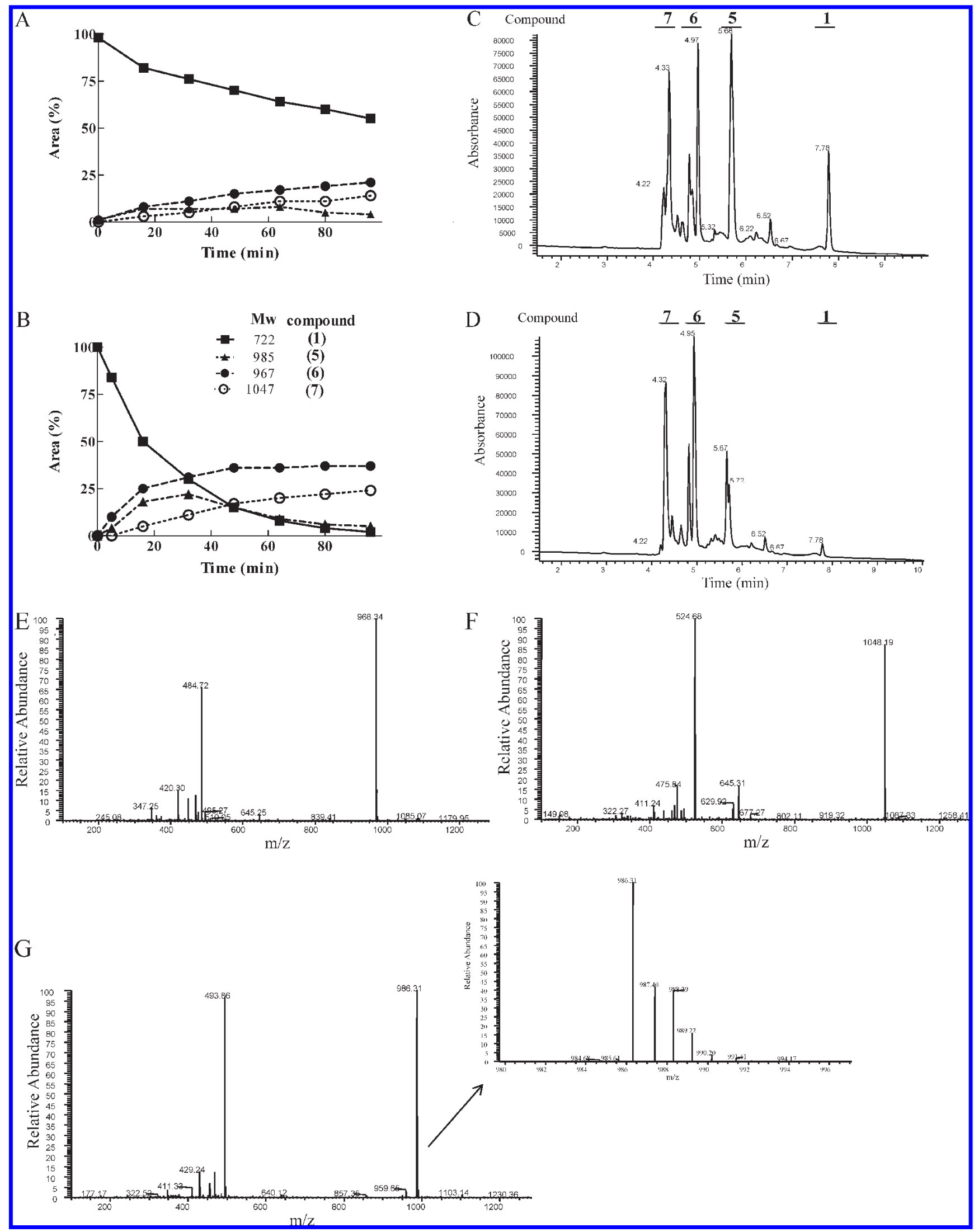

FIgURE 2: Time course of the brostallicin-GSH reaction followed by the HPLC-UV/MS method. Analysis was performed at different time intervals on a reaction mixture containing GSH, brostallicin, and either GSTM2-2 (A) or GSTP1-1 (B). For experimental conditions, see Experimental Procedures. The peak area of each species is expressed as the percent of the brostallicin peak area at time zero. Panels $\mathrm{C}$ and $\mathrm{D}$ show the HPLC-UV chromatograms for the reactions with GSTP1-1 (at $10 \mathrm{~min}$ ) and GSTM2-2 (at 30 min), respectively. Panels E-G show the ESI mass spectra of compounds $\mathbf{6 , 7}$, and $\mathbf{5}$. Under the experimental conditions utilized, both the singly and doubly charged peaks were detected for each compound. The inset of panel $\mathrm{G}$ is an expanded view of the peak at $\mathrm{m} / \mathrm{z} 986$ (compound 5) showing the characteristic splitting due to the presence of two isotopes of chlorine, ${ }^{35} \mathrm{Cl}$ and ${ }^{37} \mathrm{Cl}$. 


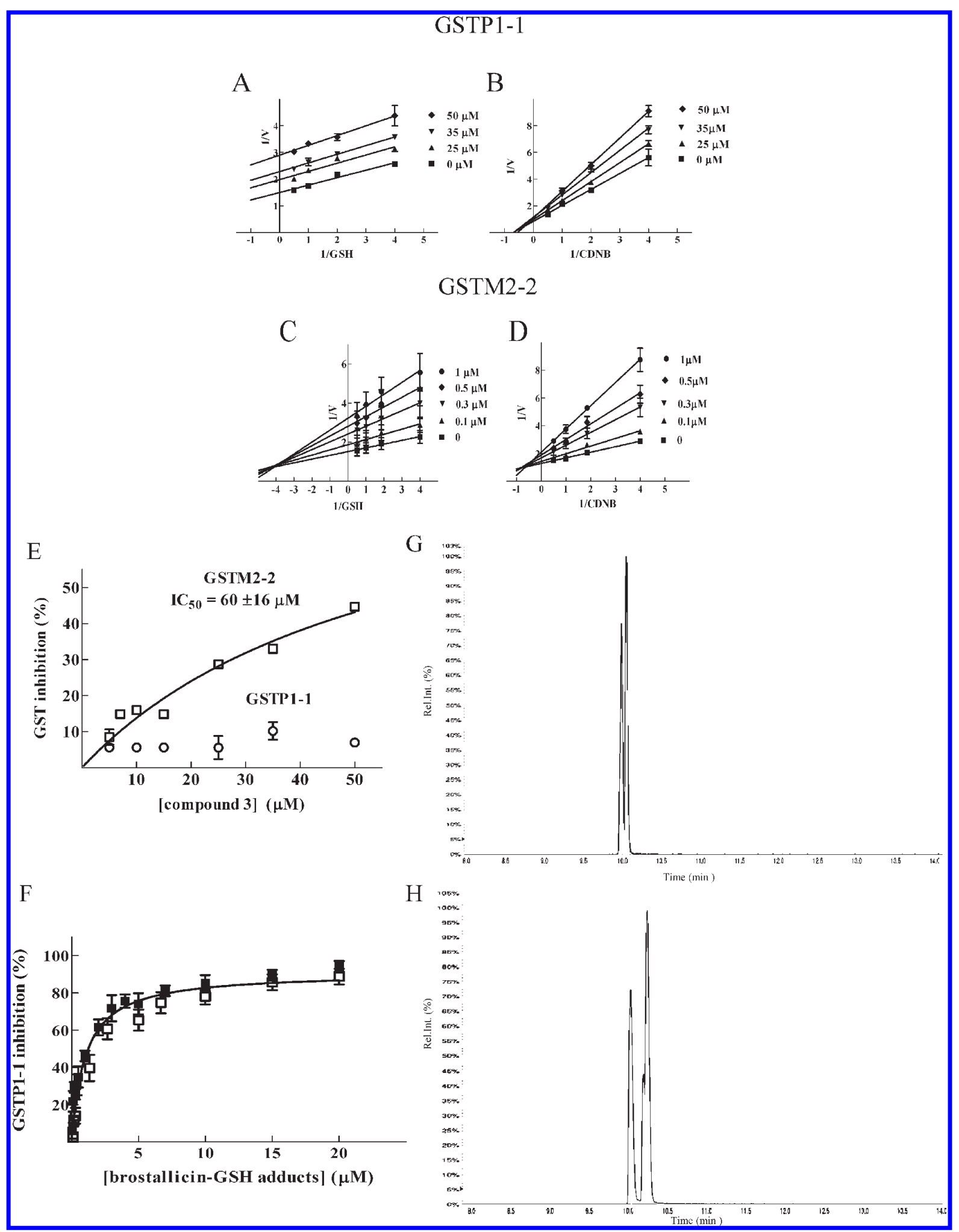

FIGURE 3: Inhibition of GSTP1-1 and GSTM2-2 by either brostallicin or compound 3, 6, or 7. Experiments were performed at pH 6.5 and $25{ }^{\circ} \mathrm{C}$. (A-D) The brostallicin concentration was varied between 0 and $50 \mu \mathrm{M}$ with GSTP1-1 and between 0 and $1 \mu \mathrm{M}$ with GSTM2-2. At each inhibitor concentration, the concentration of either GSH or CDNB was varied from 0.25 to $2 \mathrm{mM}$, while the cosubstrate concentration was maintained constant at $1 \mathrm{mM}$. Initial velocity data are reported as Lineweaver-Burk plots. (E) The concentration of the debrominated derivative of brostallicin, compound 3, was varied between 0 and $50 \mu \mathrm{M}$, while the concentrations of CDNB and GSH were maintained constant at $1 \mathrm{mM}$. (F) The concentrations of compounds 6 and 7 were varied between 0 and $20 \mu \mathrm{M}$, while the concentrations of CDNB and GSH were maintained constant at $1 \mathrm{mM}$ : compound $\mathbf{6}(\square)$ and a mixture of compounds $\mathbf{6}$ and $\mathbf{7}(\mathbf{\square})$. Data are reported as the percent of GST inhibition, and the solid lines represent the best fit of data to a simple binding isotherm. Points are means of four independent experiments; bars show the standard deviation. (G and H) HPLC-MS analysis of compound $\mathbf{6}(\mathrm{G})$ and a mixture of compounds $\mathbf{6}$ and 7 (H) obtained enzymatically as reported in Experimental Procedures. The total ion chromatograms of the MRM transitions of compounds $6(\mathrm{~m} / z$ $968 / 695$ and 968/839) and 7 ( $m / z$ 1048/645 and 1048/951) are shown. The chromatograms are acquired by simultaneously selecting the MRM transitions of both compounds 6 and 7 . 


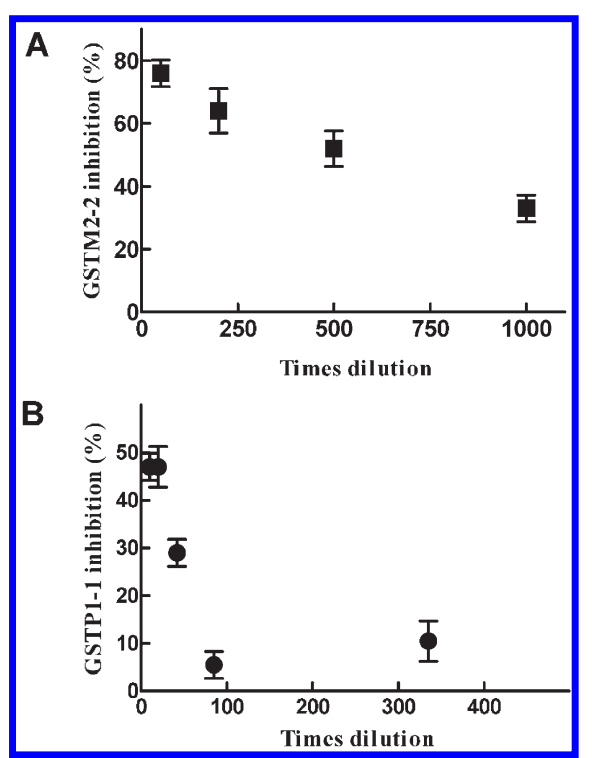

Figure 4: Brostallicin-GSH adducts 6 and 7 do not cause irreversible inhibition of GSTs. GSTM2-2 (A) and GSTP1-1 (B) were incubated at a constant $\mathrm{GSH}(1 \mathrm{mM})$ and brostallicin concentrations (100 $\mu \mathrm{M}$ with GSTM2-2 and $400 \mu \mathrm{M}$ with GSTP1-1). After a suitable incubation time for conversion of brostallicin in its GSH derivatives, different aliquots of the incubation mixture were assayed for GST activity after dilution in $1 \mathrm{~mL}$ (final volume) of standard assay mixture. All experiments were performed in triplicate. Data are expressed as means \pm the standard deviation.

The main product of both reactions was represented by a species at $m / z$ 968, identified as brostallicin-GSH adduct $\mathbf{6}$ in which bromine is replaced by one hydroxy group (Figure $2 \mathrm{C}-\mathrm{E}$ ). Another product at $m / z 1048$ was identified as brostallicin-GSH adduct 7 in which bromine is replaced by one phosphate group (Figure 2C,D,F). GSH-brostallicin $\alpha$-bromoamido derivative $\mathbf{4}$ was not detected under these conditions, confirming the hypothesis that brostallicin, after the addition of GSH, forms a highly reactive intermediate which substitutes bromine with other species present in solution $(22-24)$. However, a long-lived transient species has been observed at $m / z$ 986. This intermediate has been identified as GSH-brostallicin $\alpha$-chloroamido derivative $\mathbf{5}$ in which bromine is replaced by chlorine ions from the reaction medium (Figure 2C,D,G). The presence of chlorine in this species is confirmed by the mass spectrum related to the corresponding chromatographic peak where the protonated molecular ion shows the characteristic splitting and abundance ratio of two isotopic species, ${ }^{35} \mathrm{Cl}$ and ${ }^{37} \mathrm{Cl}$ (Figure $2 \mathrm{G}$, inset). During the experiment, this transient reactive species undergoes a relatively slow $\left(t_{1 / 2} \sim 45-50 \mathrm{~s}\right)$ conversion to stable $\alpha$-hydroxy derivative 6 and $\alpha$-phosphate derivative 7. This hypothesis is further supported by the evidence that when the reaction medium was deprived of chloride ions, using sodium acetate buffer, the transient species at $m / z 986$ was not observed while a new acetate derivative (compound 8 ) was detected (data not shown).

Inhibition of GSTP1-1 and GSTM2-2 Isoenzymes by Brostallicin and Its Derivatives. The affinity of brostallicin for human isoenzymes GSTP1-1 and GSTM2-2 was estimated at $\mathrm{pH}$ 6.5 by following the effect of increasing drug concentrations on the initial velocity of the reaction between GSH and CDNB. Since the rate of reaction between GSH and CDNB is more than 100 times higher than the rate of reaction between GSH and brostallicin, we can assume that almost no brostallicin is converted into products within the experimental observation time. The initial velocity data obtained from inhibition studies are represented as Lineweaver-Burk plots. The patterns obtained suggest that brostallicin behaves like a competitive inhibitor of GSTP1-1, with respect to the cosubstrate CDNB (Figure 3B), while brostallicin behaves more like an uncompetitive inhibitor with respect to GSH (Figure 3A). With GSTM2-2, brostallicin behaves like a mixed-type inhibitor with respect to both substrates (Figure 3C,D). Inhibitor constants were determined by replot analysis of the primary reciprocal plots according to the method of Segel (18). With GSTP1-1, the inhibition constants are as follows: $K_{\mathrm{iGSH}}=28 \pm 0.1 \mu \mathrm{M}$, and $K_{\mathrm{iCDNB}}=37 \pm 0.1 \mu \mathrm{M}$. With GSTM2-2, the mixed-type inhibition yields two series of $K_{\mathrm{i}}$ values: $K_{\mathrm{i}}$ values for the competitive component $\left(K_{\mathrm{iGSH}}=0.6 \pm\right.$ $0.1 \mu \mathrm{M}$, and $\left.K_{\mathrm{iCDNB}}=0.4 \pm 0.1 \mu \mathrm{M}\right)$ and $K_{\mathrm{i}}$ values for the uncompetitive component $\left(K_{\mathrm{iGSH}}=1.0 \pm 0.4 \mu \mathrm{M}\right.$, and $K_{\mathrm{iCDNB}}=$ $1.7 \pm 0.3 \mu \mathrm{M})$. Therefore, brostallicin is much more efficient in inhibiting GSTM2-2 than in inhibiting GSTP1-1.

Bromine is an essential structural requirement for a tight interaction with the GST isoenzymes. In fact, the debrominated derivative of brostallicin (compound 3) is almost completely ineffective as an inhibitor of GSTP1-1 and shows, with GSTM22 , an $\mathrm{IC}_{50}$ of approximately $60 \mu \mathrm{M}$, a value 100 times higher than that observed with brostallicin under the same experimental conditions (GSH and CDNB concentrations constant at 1 $\mathrm{mM}$ ) (Figure 3E).

We also analyzed the inhibition effect of GSH-brostallicin adducts 6 and 7 on the reaction between CDNB and GSH catalyzed by GSTP1-1. When a mixture of these compounds was utilized, a quite hyperbolic inhibition trend was obtained (Figure $3 \mathrm{~F}$ ) in which one phase was clearly resolved $\left(\mathrm{IC}_{50} \sim 1\right.$ $\mu \mathrm{M})$. An identical behavior was observed when the experiments were repeated employing only compound $\mathbf{6}$ (Figure $3 \mathrm{~F}$ ). Compounds $\mathbf{6}$ and 7 differ only in the group bound to the $\alpha$-carbon of the carboxamido moiety. Therefore, we assume that this group does not play a role in the interaction with GSTP1-1 and that the affinity of both compounds $\mathbf{6}$ and $\mathbf{7}$ for the enzyme is similar to that of the transient $\alpha$-chloroamido species $\mathbf{5}$.

Brostallicin and Its GSH Adducts Do Not Irreversibly Inactivate GSTP1-1 and GSTM2-2. The interaction of GSTs with $\alpha, \beta$-unsaturated compounds, such as brostallicin, typically leads to irreversible inhibition of these enzymes (25). The same mechanism can be hypothesized for reactive intermediates 4 and $\mathbf{5}$, which might covalently interact with the nucleophilic residues of the enzyme. To evaluate the possibility of a covalent inhibition, we subjected either GSTP1-1 or GSTM2-2 to a prolonged incubation with brostallicin and GSH to convert brostallicin quantitatively into its GSH derivatives. Then, we determined the effect of dilution on the degree of enzyme inhibition. Complete restoration of the original catalytic activity was observed after dilution, ruling out the possibility of an irreversible inactivation of the GSTs (Figure 4).

Spectrofluorometric Evidence of the Reaction between Brostallicin and GSH. The low intrinsic fluorescence of brostallicin undergoes a time-dependent increase in the presence of GSH and either GSTP1-1 or GSTM2-2 (Figure 5A). This spectral change of brostallicin does not occur in the absence of either GSH or GST. Thus, the increase in the fluorescence of brostallicin has been attributed to the exchange of the halogen group with either the hydroxy or the phosphate group present in solution, giving compound $\mathbf{6}$ or $\mathbf{7}$, respectively. The rate of this event increases linearly with the amount of GST (Figure 5B), 


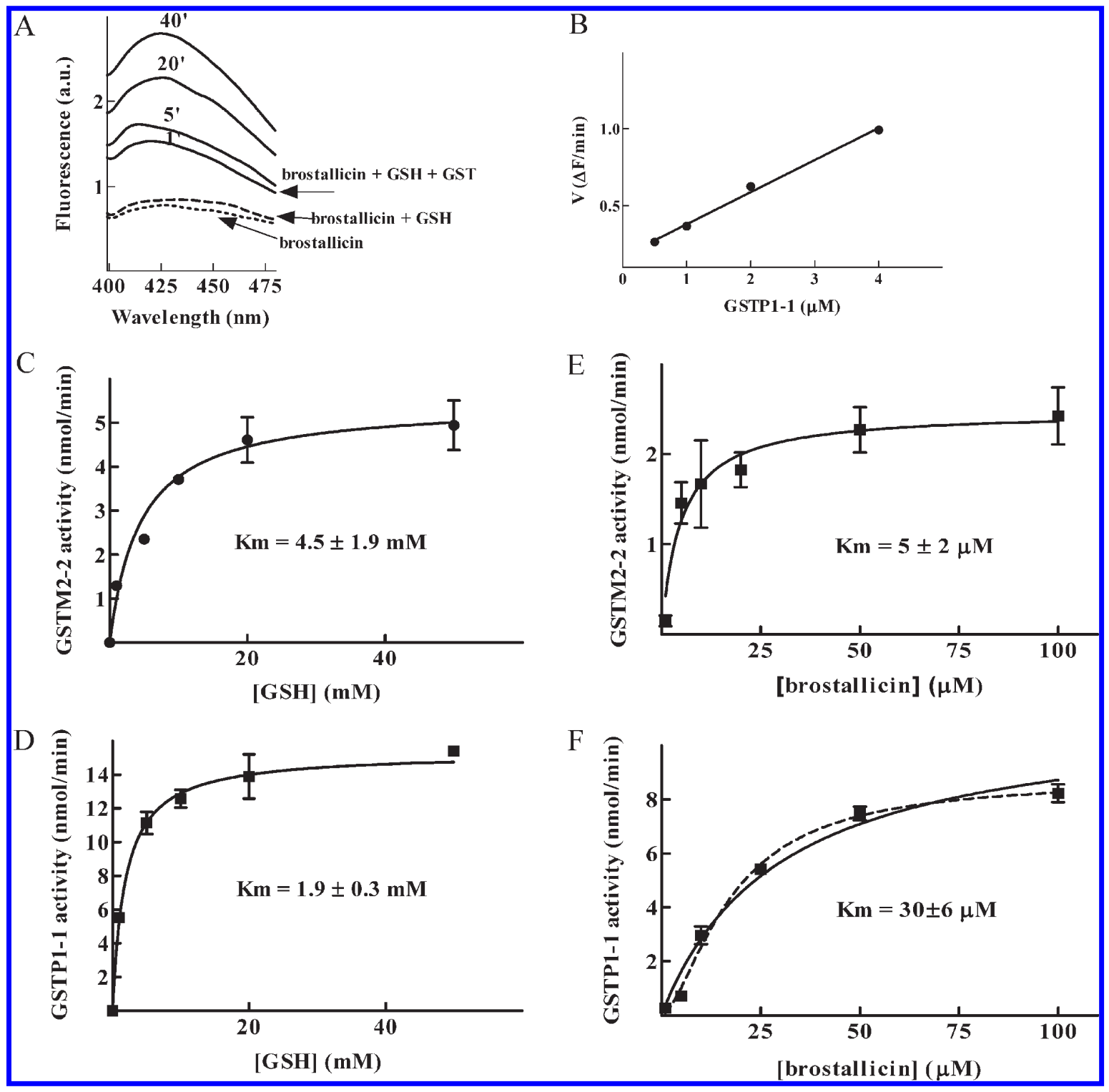

FIGURE 5: Spectrofluorometric evidence of the reaction between GSH and brostallicin. (A) The fluorescence spectra of $50 \mu \mathrm{M}$ brostallicin in 0.1 M potassium phosphate buffer ( $\mathrm{pH}$ 6.5) were recorded in the absence $(\cdots)$ and presence of $1 \mathrm{mM} \mathrm{GSH} \mathrm{(---),1} \mathrm{mM} \mathrm{GSH,} \mathrm{and} \mathrm{0.2} \mu$ M GSTP1-1 $(-)$. Spectra were recorded at different incubation times from 1 to $40 \mathrm{~min}$ (excitation at $370 \mathrm{~nm}$ ). (B) Rate of spectral change $(V)$ as function of GST concentration. Brostallicin $(25 \mu \mathrm{M})$ was reacted at $\mathrm{pH} 6.5$ and $25^{\circ} \mathrm{C}$ with $\mathrm{GSH}(1 \mathrm{mM})$ in the presence of an increasing amount of GSTP1-1 (from 0.5 to $4 \mu \mathrm{M}$ ). The reaction was followed at $425 \mathrm{~nm}$ (excitation at $370 \mathrm{~nm}$ ) by fluorometry, and the velocity was measured immediately after the addition of the enzyme. $(\mathrm{C}-\mathrm{F})$ Effect of either brostallicin or GSH concentration on the initial velocity of the reaction. Experiments were conducted at $\mathrm{pH} 6.5$ and $25^{\circ} \mathrm{C}$, with either $1 \mu \mathrm{M}$ GSTM2-2 (C and E) or $1 \mu \mathrm{M}$ GSTP1-1 (D and F). We obtained the dependence of the initial velocity on GSH concentration by varying the GSH concentration from 1 to $20 \mathrm{mM}$ and keeping the brostallicin concentration constant at $50 \mu \mathrm{M}$ (C and D). We analyzed the effect of brostallicin by varying the brostallicin concentration from 1 to $100 \mu \mathrm{M}$ and keeping the GSH concentration constant at $1 \mathrm{mM}$ (E and F). The solid lines represent the best fit of data to a simple binding isotherm. The experimental data reported in panel $\mathrm{F}$ were also fitted to a sigmoidal equation $(\cdots)$ to highlight the nonhyperbolic trend. The conversion of arbitrary fluorescence units into nanomoles of product was based on a calibration curve built using known amounts of preformed compounds $\mathbf{6}$ and 7 . All experiments were performed six times. Data are expressed as means \pm the standard deviation.

confirming that the enzyme promotes the reaction leading to increased fluorescence. On the basis of this evidence, we have developed a new continuous fluorometric assay for studying the kinetics of the reaction between brostallicin and GSH in the presence of GSTs. Steady-state kinetic analysis of the reaction confirms that GSTM2-2 $\left(k_{\text {cat }} / K_{\text {mbrostallicin }}=4 \mathrm{mM}^{-1} \mathrm{~s}^{-1}\right)$ is a less efficient catalyst toward brostallicin compared to GSTP1-1 $\left(k_{\text {cat }} / K_{\text {mbrostallicin }}=11 \mathrm{mM}^{-1} \mathrm{~s}^{-1}\right)$. The specificity constants reported above were calculated from initial velocity versus brostallicin concentration plots, obtained at saturating GSH concentrations and after subtraction of the rate of the nonenzymatic reaction (data not shown). Moreover, in the presence of
GSTM2-2, the apparent Michaelis constants for GSH and brostallicin $\left(K_{\mathrm{mGSH}}=4.5 \mathrm{mM}\right.$, at $50 \mu \mathrm{M}$ brostallicin, and $K_{\text {mbrostallicin }}=5 \mu \mathrm{M}$, at $1 \mathrm{mM} \mathrm{GSH}$ ) are higher than the apparent dissociation constants found for these substrates $\left[K_{\mathrm{dGSH}} \leq 50\right.$ $\mu \mathrm{M}(26)$, and $\left.K_{\text {ibrostallicin }} \sim 0.5 \mu \mathrm{M}\right]$ (Figure $5 \mathrm{C}$,E). This suggests that GSTM2-2 does not follow a rapid equilibrium Michaelis-Menten mechanism. However, the low catalytic activity of the GSTM2-2 isoenzyme and its high affinity for brostallicin prevent an accurate kinetic study.

The dependence of GSTP1-1 activity on brostallicin concentration shows a cooperative trend (Figure 5F); therefore, a more detailed analysis of the reaction between GSH and bros- 
Scheme 1: Kinetic Scheme for the Reaction Catalyzed by GSTP1-1 ${ }^{a}$

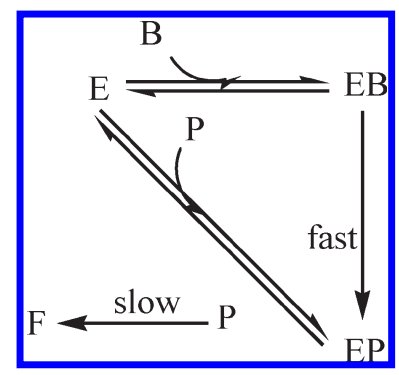

${ }^{a}$ The mechanism assumes that the enzyme consists of two subunits that are in identical conformations and behave independently; thus, only one subunit is shown. Moreover, GSH (present at a high and almost constant concentration) is omitted for the sake of simplicity. The catalytic step involves the rapid formation of the intermediate product $(\mathrm{P})$ and its slow conversion into the final fluorescent product(s) (F). Abbreviations: E, GSTP1-1; B, brostallicin; P, compound 5; F, mixture of compounds 6 and 7 .

Table 2: Kinetic Parameters for the Brostallicin-GSH Reaction Catalyzed by GSTP1-1 ${ }^{a}$

\begin{tabular}{lc}
\hline kinetic parameter & value $\pm \mathrm{SD}$ \\
\hline${ }^{\mathrm{B}} K_{\mathrm{d}}(\mu \mathrm{M})$ & $50 \pm 19$ \\
$k_{1}\left(\mathrm{~s}^{-1}\right)$ & $0.6 \pm 0.1$ \\
${ }^{\mathrm{P}} K_{\mathrm{d}}(\mu \mathrm{M})$ & $3 \pm 1$ \\
$k_{2}\left(\mathrm{~s}^{-1}\right)$ & $0.026 \pm 0.001$ \\
\hline
\end{tabular}

${ }^{a}$ Kinetic and thermodynamic constants were obtained by the best fit to Scheme 1 of the fluorescence traces of the reaction between GSH and brostallicin at different GSTP1-1 concentrations. ${ }^{\mathrm{B}} K_{\mathrm{d}}$ is the dissociation constant for the binding of brostallicin to GSTP1-1. $k_{1}$ is the rate constant for the conversion of brostallicin into the transient product $\mathrm{P} .{ }^{\mathrm{P}} K_{\mathrm{d}}$ is the dissociation constant for the binding of P to GSTP1-1. $k_{2}$ is the rate constant for the conversion of $\mathrm{P}$ into the fluorescence product(s) (F). SD is the standard deviation.

tallicin catalyzed by GSTP1-1 has been performed to define this behavior.

Kinetic Analysis of the Brostallicin-GSH Reaction Catalyzed by GSTP1-1. We carefully analyzed the fluorescence time courses of the reaction of GSH and brostallicin in the presence of different amounts of GSTP1-1. The experimental traces were best fitted to a minimal reaction mechanism (Scheme 1), to yield the microscopic rate constants and the thermodynamic constants listed in Table 2. In the proposed kinetic scheme, the catalytic step involves the rapid formation of a GSH-brostallicin intermediate (P), identified as compound 5, which slowly converts into the final fluorescent product(s) $(\mathrm{F})$, identified as a mixture of compounds 6 and 7 . The presence of this second slow reaction explains well both the autocatalytic fluorescence traces (data not shown) and the nonhyperbolic dependence of the initial velocity on brostallicin concentration (Figure 5F). The estimation of the thermodynamic constants utilized for fitting the experimental data to Scheme 1 has been derived from different experimental approaches. (a) The dissociation constant for the binding of brostallicin to GSTP1-1 was obtained by inhibition studies (see Figure 3A,B) using brostallicin as an inhibitor of the reaction between CDNB and GSH. (b) The dissociation constant for the binding of the product(s) to GSTP1-1 was obtained by inhibition experiments using compounds $\mathbf{6}$ and $\mathbf{7}$ as inhibitors of the reaction between CDNB and GSH (Figure 3F).
Evidence at Physiological pH: Brostallicin Activation Requires GST, and the $\alpha$-Chloro Derivative 5 Binds Covalently to $D N A$. The reactivity of nucleophiles is influenced by $\mathrm{pH}$; therefore, the reaction between brostallicin and GSH might be enzyme-independent at physiological $\mathrm{pH}$. However, we observed that $10 \mu \mathrm{M}$ brostallicin [the highest drug concentration utilized on tumor cells (7)] reacts very slowly with GSH at pH 7.4 and GSTs are required to achieve an effective brostallicin activation rate (Figure 6A). Moreover, we tested the ability of either brostallicin or its $\alpha$-chloro derivative 5 to interact with DNA at physiological $\mathrm{pH}$. In fact, DNA minor groove binders make up a class of anticancer agents whose activity in tumor cells has been correlated to their ability to alkylate DNA in a highly sequence-specific manner (27). The sequence-specific covalent DNA interaction of brostallicin was analyzed by the Taq polymerase stop assay. The polyacrylamide gel autoradiography reported in Figure 6B shows that brostallicin alone, in the absence of the GSH/GST system, did not alkylate DNA (lane 5), while a band was observed when the GSH/GST system was added to the reaction mixture (lane 6). Compound 5 in the absence of was GSH/GST system able to bind covalently to DNA (lane 7) and with the same sequence specificity as brostallicin in the presence of the GSH/GST system. Both brostallicin and compound $\mathbf{5}$ bind to a sequence (AAAG) that differs from the DNA minor groove binding specificity of tallimustine (lanes 3 and 4). Thus, our data indicate that the GSH/GST system converts brostallicin into the reactive molecule $\mathbf{5}$ which is able to covalently interact with the same DNA sequence of brostallicin. These data support the hypothesis that compound $\mathbf{5}$ may represent the critical intermediate in the activation mechanism of brostallicin (Scheme 2).

\section{DISCUSSION}

Since 2001, brostallicin has been extensively investigated, because of its promising antitumor activity profile in experimental models and its enhanced activity in cancer cells with high GSH/GST levels (7). This distinctive activation mechanism exploits a recognized vulnerability found in many cancer cells, as the GSH/GST detoxifying pathways are often upregulated in human tumors and a cause of reduced responsiveness (i.e., chemoresistance) to commonly used anticancer agents. However, direct evidence of the interaction between brostallicin and the GSH/GST system and the mechanism of drug activation was lacking. In this work, we have provided evidence that the $\mathrm{GSH} / \mathrm{GST}$ system plays a key role in determining the sensitivity of cells, as overexpression of mu and pi class GSTs increases brostallicin cytotoxicity. We clearly show that brostallicin binds both GSTP1-1 and GSTM2-2, the most abundant GST isoenzymes in tumor cells, with an affinity for GSTM2-2 almost 2 orders of magnitude higher than that for GSTP1-1. A careful investigation of the $\mathrm{H}$-site's architecture of these isoenzymes reveals that residues Ile104 and Arg13, in the GSTP1-1 active site, are replaced with Ala111 and Leu12 in GSTM2-2 (29, 30). Therefore, the cumbersome brostallicin molecule may better accommodate the large active site cleft of the mu class isoenzyme. Both GST isoenzymes catalyze the addition of GSH to brostallicin. GSTM2-2 catalyzes the reaction at a rate lower than that of GSTP1-1; however, given its high affinity, it is fully active at brostallicin concentrations that are effective on tumor cells. This suggests that brostallicin may also be suitable for the treatment of tumors selectively expressing mu class GST. A minimum reaction 


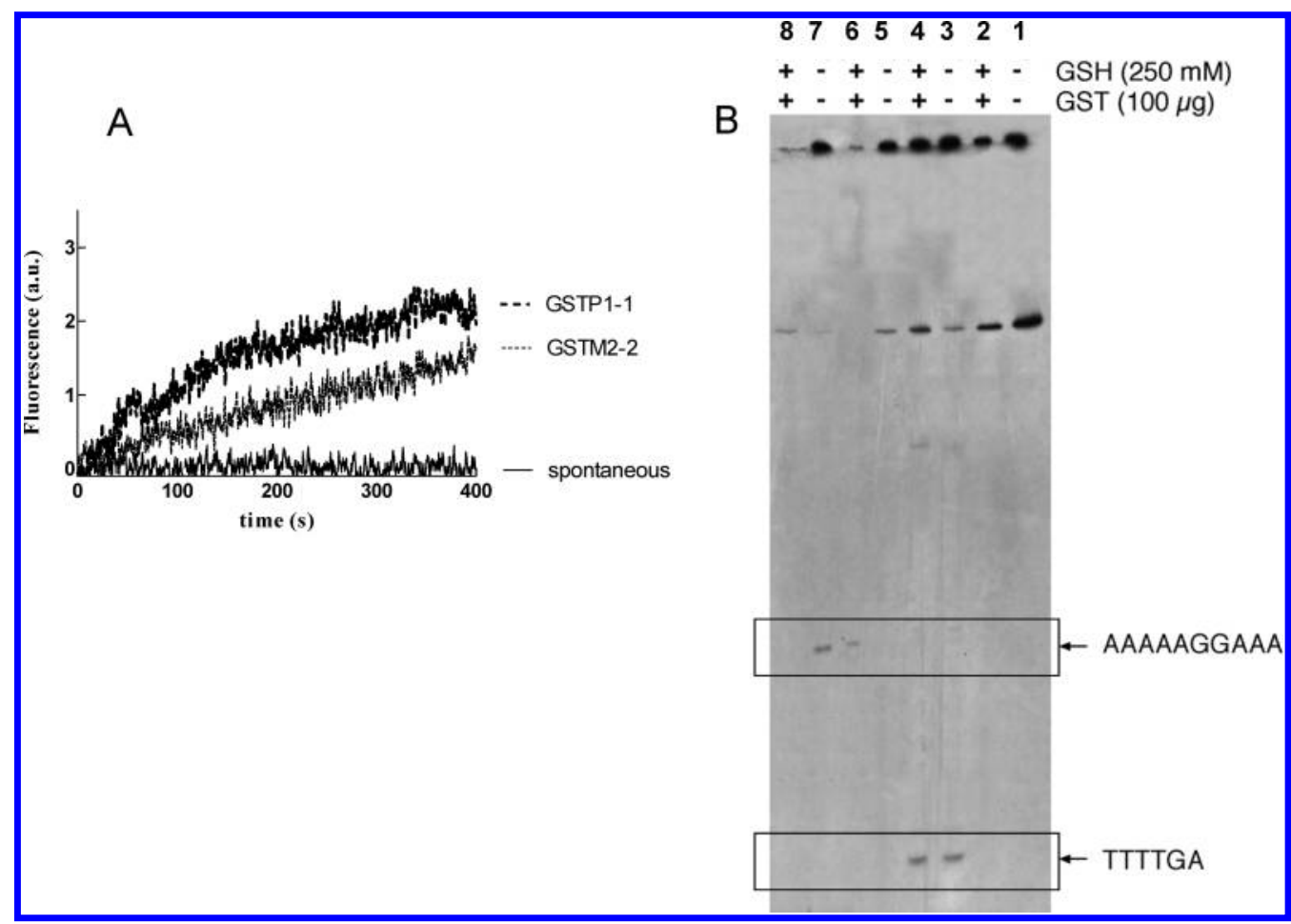

FIgURE 6: (A) Fluorescence time courses of the reaction between $\mathrm{GSH}(1 \mathrm{mM})$ and brostallicin $(10 \mu \mathrm{M})$, performed at $\mathrm{pH} 7.4$ and $25^{\circ} \mathrm{C}$ in the absence (spontaneous) and presence of either GSTP1-1 $(1 \mu \mathrm{M})$ or GSTM2-2 $(1 \mu \mathrm{M})$. (B) Autoradiography of a typical Taq stop assay on topoisomerase II cDNA after drug treatment. Compound $\mathbf{5}$ was able to bind covalently to DNA in the absence of the GSH/GST system (lane 7). Brostallicin alone did not alkylate DNA (lane 5), while a band was observed when the GSH/GST system was added to the reaction mixture (lane 6). In the absence of drugs, the GSH/GST system did not induce any alteration able to block Taq polymerase (lanes 1 and 2). As a control, tallimustine was tested (lanes 3 and 4). The experiment was performed as described in Experimental Procedures. Arrows denote the alkylated regions.

Scheme 2: Proposed Mechanism for Brostallicin Activation by the GST/GSH System $(8,28)$

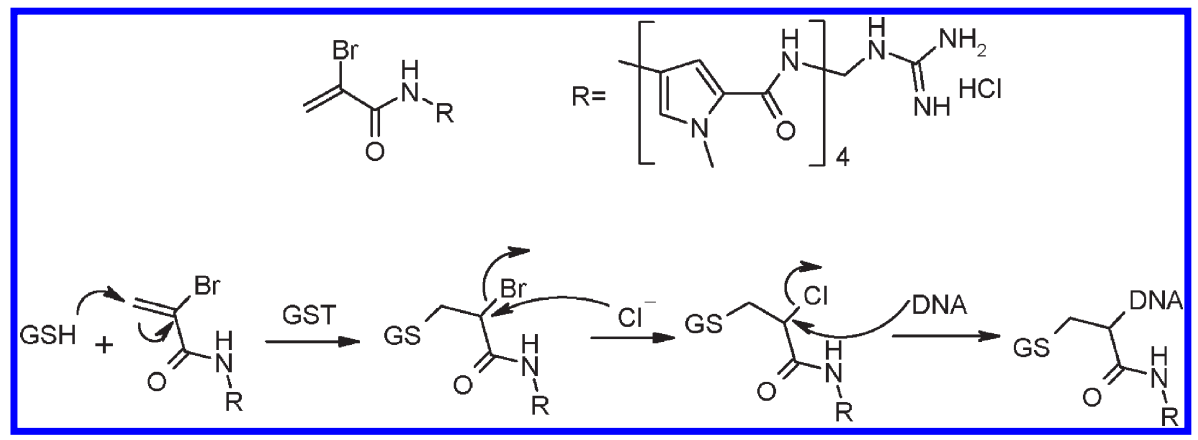

mechanism has been proposed to satisfactorily describe the GSTP1-1-catalyzed reaction of GSH with brostallicin. This mechanism implies that the enzyme catalyzes the formation of one intermediate brostallicin derivative which is slowly converted into a few stable products. This agree with HPLC-UV/MS analysis which reveals the presence of a transient species (compound 5) that slowly reacts with the surrounding species generating fluorescent derivatives $\mathbf{6}$ and 7. These compounds are very stable in solution as the $\alpha$-hydroxy (compound 6) and $\alpha$-phosphate (compound 7) are bad leaving groups. Compound 5 could be inactivated by substitution of the reactive chlorine with an additional GSH molecule whose concentration is in the millimolar range $(0.5-10 \mathrm{mM})$ in mammalian cells. However, under our experimental conditions, the amount of derivative bearing a second molecule of GSH is negligible; this may be due to the steric hindrance between the two GSH molecules. The relatively long living intermediate $5\left(t_{1 / 2} \sim 45-50 \mathrm{~s}\right.$ under our experimental conditions) is very likely transiently populated to a significant amount also inside the cells, where chloride ions are abundant, and may represent the real active form of the drug. This hypothesis is supported by the Taq polymerase stop assay showing that compound $\mathbf{5}$ is able to bind covalently to DNA with the same DNA sequence specificity as the parent drug, in the presence of both GSH and GSTs.

The mechanism of the reaction herein described for brostallicin is similar to that reported by Creighton et al. (31) for the activation of 2-crotonyloxymethyl-2-cycloalkenone drugs. Likewise, a substrate is transformed into a toxic product by GST. The reaction is a multistep process, involving the formation of a reactive GS conjugate that reacts spontaneously with other GSH molecules giving stable glutathionylated adducts. The apparent rates of formation and degradation of the active species are on the same order of magnitude as the rates we observed, leading to the potential therapeutic use of these pro-drugs. In conclusion, we have explained why, unlike that of most anticancer drugs (32), brostallicin efficacy takes advantage of high intracellular levels of 
both GSH and GSTs. Our data both reinforce and further the understanding of the targeted activation of brostallicin. Considering that several human tumors display increased levels of pi and/or mu class GSTs $(12,13)$, these data highlight how this activation relates to the established anticancer activity of brostallicin.

\section{REFERENCES}

1. Romagnoli, R., Baraldi, P. G., Cruz-Lopez, O., Lopez-Cara, C., and Preti, D. (2009) $\alpha$-Halogenoacrylic derivatives of antitumor agents. Mini Rev. Med. Chem. 9, 81-94.

2. Pook, S. H., Toh, C. K., and Mahendran, R. (2006) Combination of thiol antioxidant Silibinin with Brostallicin is associated with increase in the anti-apoptotic protein Bcl-2 and decrease in caspase 3 activity. Cancer Lett. 238, 146-152.

3. Sabatino, M. A., Colombo, T., Geroni, C., Marchini, S., and Broggini, M. (2003) Enhancement of in vivo antitumor activity of classical anticancer agents by combination with the new, glutathione-interacting DNA minor groove-binder, brostallicin. Clin. Cancer Res. 9, 5402-5408.

4. Geroni, C., Marchini, S., Cozzi, P., Galliera, E., Ragg, E., Colombo, T., Battaglia, R., Howard, M., D'Incalci, M., and Broggini, M. (2002) Brostallicin, a novel anticancer agent whose activity is enhanced upon binding to glutathione. Cancer Res. 62, 2332-2336.

5. Cozzi, P. (2001) A new class of cytotoxic DNA minor groove binders: $\alpha$-halogenoacrylic derivatives of pyrrolecarbamoyl oligomers. Farmaco 56, 57-65.

6. Fedier, A., Fowst, C., Tursi, J., Geroni, C., Haller, U., and Marchini, S. (2003) Brostallicin (PNU-166196) a new DNA minor groove binder that retains sensitivity in DNA mismatch repair-deficient tumour cells. Br. J. Cancer 89, 1559-1565.

7. Guirouilh-Barbat, J., Zhang, Y.-W., and Pommier, Y. (2009) Induction of glutathione-dependent DNA double-strand breaks by the novel anticancer drug brostallicin. Mol. Cancer Ther. 8, 1985-1994.

8. Beria, I., Baraldi, P. G., Cozzi, P., Caldarelli, M., Geroni, C., Marchini, S., Mongelli, N., and Romagnoli, R. (2004) Cytotoxic $\alpha-$ halogenoacrylic derivatives of distamycin A and congeners. $\underline{\text { J.Med. }}$ Chem. 47, 2611-2623.

9. Cozzi, P. (2003) The discovery of a new potential anticancer drug: A case history. Farmaco 58, 213-220.

10. Broggini, M., Marchini, S., Fontana, E., Moneta, D., Fowst, C., and Geroni, C. (2004) Brostallicin: A new concept in minor groove DNA binder development. Anticancer Drugs 15, 1-6.

11. Townsend, D. M., and Tew, K. D. (2003) The role of glutathione-Stransferase in anti-cancer drug resistance. Oncogene 22, 7369-7375.

12. Tew, K. D., Monks, A., Barone, L., Rosser, D., Akerman, G., Montali, J. A., Wheatley, J. B., and Schmidt, D. E., Jr. (1996) Glutathione-associated enzymes in the human cell lines of the National Cancer Institute Drug Screening Program. Mol. Pharmacol. 50, $149-159$.

13. Moscow, J. A., Townsend, A. J., and Cowan, K. H. (1989) Elevation of pi class glutathione S-transferase activity in human breast cancer cells by transfection of the GST pi gene and its effect on sensitivity to toxins. Mol. Pharmacol. 36, 22-28.

14. Townsend, A. J., Chen-Pei, D. Tu., and Cowan, K. H. (1992) Expression of human mu or alpha class glutathione S-transferases in stably transfected human MCF-7 breast cancer cells: Effect on cellular sensitivity to cytotoxic agents. Mol. Pharmacol. 41, 230236.
15. Lo Bello, M., Battistoni, A., Mazzetti, A. P., Board, P. G., Muramatsu, M., Federici, G., and Ricci, G. (1995) Site-directed mutagenesis of human glutathione transferase P1-1. Spectral, kinetic, and structural properties of Cys-47 and Lys-54 mutants. J. Biol. Chem. 270, 1249-1253.

16. Habig, W. H., and Jakoby, W. B. (1981) Assays for differentiation of glutathione S-transferases. Methods Enzvmol. 77, 398-405.

17. Gill, S. C., and von Hippel, P. H. (1989) Calculation of protein extinction coefficients from amino acid sequence data. Anal. Biochem. 182, 319-326.

18. Segel, H. I. (1993) Enzyme Kinetic Behavior and Analysis of Rapid Equilibrium and Stady-State Enzyme System, John Wiley \& Sons, Inc., New York.

19. Hoops, S., Sahle, S., Gauges, R., Lee, C., Pahle, J., Simus, N., Singhal, M., Xu, L., Mendes, P., and Kummer, U. (2006) COPASI: A COmplex PAthway SImulator. Bioinformatics 22, 3067-3074.

20. Ponti, M., Forrow, S. M., Souhami, R. L., D'Incalci, M., and Hartley, J. A. (1991) Measurement of the sequence specificity of covalent DNA modification by antineoplastic agents using Taq DNA polymerase. Nucleic Acids Res. 19, 2929-2933.

21. Marchini, S., Cozzi, P., Beria, I., Geroni, C., Capolongo, L., D'Incalci, M., and Broggini, M. (1998) Sequence-specific DNA alkylation of novel tallimustine derivatives. Anti-Cancer Drug Des. 13, 193-205.

22. Bredereck, H., Gompper, R., and Theilig, G. (1954) Formamide reactions. III. Reactions of halogen compounds with formamide. Chem. Ber. 87, 537-546.

23. Guest, H. H. (1947) Isomeric chlorinated long-chain esters. J. Am. Chem. Soc. 69, 300-302.

24. Nam, J., Lee, S., Kim, K., Yong, P., and Yong, S. (2002) Asymmetric syntheses of $\alpha$-mercapto carboxylic acid derivatives by dynamic resolution of $\mathrm{N}$-methyl pseudoephedrine $\alpha$-bromo esters. Tetrahedron Lett. 43, 8253-8255.

25. van Iersel, M. L., Ploemen, J. P., Lo Bello, M., Federici, G., and van Bladeren, P. J. (1997) Interactions of $\alpha, \beta$-unsaturated aldehydes and ketones with human glutathione S-transferase P1-1. Chem.-Biol. Interact. 108, 67-78.

26. Caccuri, A. M., Antonini, G., Board, P. G., Parker, M. W., Nicotra, M., Lo Bello, M., Turella, P., Federici, G., and Ricci, G. (1999) Proton release on binding of glutathione to alpha, mu and delta class glutathione transferases. Biochem. J. 344, 419-425.

27. D'Incalci, M., and Sessa, C. (1997) DNA minor groove binding ligands: A new class of anticancer agents. Expert Opin. Invest. Drugs 6, 875-884.

28. Chartier, H. (1972) Action of sulfenyl chlorides on crotonic derivatives. Bull. Soc. Chim. Fr. 7, 2887-2895.

29. Oakley, A. J., Rossjohn, J., Lo Bello, M., Caccuri, A. M., Federici, G., and Parker, M. W. (1997) The three-dimensional structure of the human pi class glutathione transferase P1-1 in complex with the inhibitor ethacrynic acid and its glutathione conjugate. Biochemistrv $36,576-585$.

30. Raghunathan, S., Chandross, R. J., Kretsinger, R. H., Allison, T. J., Penington, C. J., and Rule, G. S. (1994) Crystal structure of human class mu glutathione transferase GSTM2-2. Effects of lattice packing on conformational heterogeneity. J. Mol. Biol. 238, 815-832.

31. Hamilton, D. S., Zhang, X., Ding, Z., Hubatsch, I., Mannervik, B., Houk, K. N., Ganem, B., and Creighton, D. J. (2003) Mechanism of the Glutathione Transferase-Catalyzed Conversion of Antitumor 2Crotonyloxymethyl-2-cycloalkenones to GSH Adducts. J. Am. Chem. Soc. 125, 15049-15058.

32. Townsend, D. M., Findlay, V. L., and Tew, K. D. (2005) Glutathione S-transferases as regulators of kinase pathways and anticancer drug targets. Methods Enzymol. 401, 287-307. 